\title{
MUDANÇAS SOCIAIS, POPULAÇÃO E ESPAÇO: BUSCANDO RENOVAR AS BASES PARA O ESTUDO DESSA RELAÇÃO NA CONTEMPORANEIDADE
}

\section{Social changes, population and space: seeking to renew the foundations for the study of this relationship in contemporary times}

José Carlos Milléo Professor do Departamento de Geografia da Universidade Federal Fluminense josemilleo@id.uff.br

Artigo recebido em 12/09/2014 e aceito para publicação em 24/12/2014

http://dx.doi.org/10.12957/tamoios.2014.12809

\begin{abstract}
Resumo: $O$ presente artigo se debruça sobre as possibilidades que conceitos essencialmente ligados ao advento da modernidade possuem ou pelo menos preservam, ainda que de maneira limitada, na medida em que tais ferramentas acham-se sob forte ataque por uma parcela do pensamento científico. Alguns conceitos como, por exemplo, o progresso, o desenvolvimento ou o trabalho, básicos nas construções teóricas modernas são hoje bastante discutidos em seu conteúdo explicativo, seu alcance e sua validade. No caso deste artigo o conceito examinado em sua origem e possibilidades, especialmente no âmbito da ciência geográfica, é o de população. Referindo-o à Modernidade procuraremos esclarecer sua ligação com tal período buscando, ao mesmo tempo, compreender suas dotações e sua função dentro desta linhagem de pensamento e, por conseguinte, seu alcance e suas restrições na atualidade. Com isso pretendemos iniciar o estabelecimento de novas bases para a apropriação crítica deste conceito pelas ciências sociais e, em especial, pela Geografia.
\end{abstract}

Palavras-chave: mudanças sociais, modernidade, população, racionalidade, espaço

Abstract: This paper focuses on the possibilities concepts essentially linked to the advent of modernity have, or at least preserve albeit limited, to the extent that such tools find themselves under strong attack by a portion of the scientific community way. Some concepts as, for example, the progress or development work in modern theoretical basic constructions are now widely discussed in explaining its content, and its range and duration. In the case of this article examined the concept in its origin and possibilities, especially in the context of geographical science, is the population. Referring to the modernity sought to clarify his connection with that period seeking at the same time, understand their appropriations and their role within this line of thinking and, therefore, its range and its restrictions at present. With this we intend to initiate the establishment of new bases for critical appropriation of this concept by the social sciences and, in particular, by geography.

Keywords: social changes, modernity, population, rationality, space 


\section{INTRODUÇÃO}

Iniciamos este breve artigo propondo uma questão: a ciência social que praticamos hoje $^{1}$ acha-se à altura da magnitude das atuais mudanças sociais, no sentido de configurálas bem como de estabelecer instrumentos que as mensurem em seus processos intrínsecos? Pode parecer estranho dar início ao presente trabalho fazendo esse tipo de questionamento na medida em que não se faz outra coisa, na atualidade, que não seja constatar o volume e a velocidade das transformações sociais, às quais estamos submetidos de maneira inconteste. Essa verificação, podemos acrescentar, é roteiro inicial bastante frequente daqueles interessados em abordar algum aspecto de tais transformações, o que pode ampliar a relutância em partirmos do ponto proposto acima. Em outras palavras, que vivemos uma época de grandes mudanças e que elas se dão em graus e velocidades cada vez maiores, disso parece não restar dúvida. Bastaria, portanto, meramente tomar as ferramentas, as teorias e conceitos dos quais dispomos em nosso cotidiano de pesquisa, para mensurar e retratar as grandes mudanças sociais.

Contudo se considerarmos este cenário de modificações como correlato a uma nova fase (ou a derrocada, como alguns gostariam de pontuar) daquilo que se convencionou chamar de Modernidade, então nos parece ficar mais claro o raciocínio que guia a questão de início proposta. As teorias ou, como diria Jean-François Lyotard (1979), as "grandes narrativas" que orientaram a interpretação da própria Modernidade acham-se sob vigoroso ataque e com elas, tomadas de roldão, escoam também as ferramentas que lhe são correlatas $^{2}$. Tomemos apenas como exemplo, alguns conceitos como o progresso, o desenvolvimento ou o trabalho, pilares básicos na constituição de tais arquiteturas teóricas e hoje bastante discutidas em seu conteúdo explicativo além de seu alcance (SMOLKA,1993).

Que rebatimentos sobre a teoria geográfica podemos estabelecer, tendo em vista estes questionamentos? No estudo de diferentes populações e nas mais diversas escalas, por exemplo, temos avaliado e estabelecido parâmetros de comparação lançando mão de argumentos fortemente embasados em tais conceitos, de forma consciente ou não. Do mesmo modo a desqualificação destas ferramentas traz importantes repercussões à Geografia, dada sua forte ligação com métodos que veem nos mesmos um conteúdo explicativo imprescindível.

Assim, resta a indagação sobre o modo como poderemos nos aparelhar adequadamente em nossas tentativas de explicar as mudanças espaciais se considerarmos 
as limitações ou até mesmo o abandono a tais conceitos ou categorias (como alguns também advogam $\left.{ }^{3}\right)$.

De início, contudo, é preciso esclarecer que esse artigo não pretende esgotar as questões acima aludidas, até por que os conceitos destacados como marcas do pensamento modernista não são examinados nesse primeiro momento. Nossa contribuição adia esse ataque mais frontal às tais lacunas (contidas ou alegadas nos esquemas de pensamento da Modernidade) procurando, antes, demarcar essa aproximação mediante a utilização de outro conceito surgido no seio da Modernidade e que se converteu em fundamental ferramenta dentro das cercanias das ciências sociais, qual seja: a população.

Tomando-o como pivô ou como ponto de apoio em torno do qual são manuseados outros tantos conceitos, pensamentos e convicções tipicamente modernos, procuraremos esclarecer sua ligação com tal período para compreender sua vocação, sua função dentro deste pensamento e, por conseguinte, seu alcance e suas limitações na atualidade. Entendemos que embora não seja imprescindível, tal contorno assegura uma crítica embasada tanto à forma como os estudos dedicados às mudanças geodemográficas vem sendo conduzidos, bem como às propostas de seu aperfeiçoamento ou mesmo superação em favor de um novo viés mais adequado à contemporaneidade. Como tentaremos demonstrar aqui, na Modernidade não se constituem apenas os modos como compreenderemos as mudanças que atingem a população, mas - como anuncia (surpreendentemente) Michel Foulcault $(1978,1979)$ - se estabelece a própria forma como a temática do Homem através da emergência desse conceito passará a ser encarada.

\section{A CONSTITUIÇÃO DO CONCEITO DE POPULAÇÃO NA MODERNIDADE}

Poderíamos iniciar essa parte nos perguntando se o fato da Modernidade estar ingressando em nova fase (sua radicalização ${ }^{4}$ ou seu encerramento ${ }^{5}$ ) repercute de maneira tão importante sobre nossa noção de população e os estudos à ela correlatos. Na verdade, defendemos que isso se dá exatamente em função da visceral ligação que esse conceito tem com a Modernidade em sua fase mais pronunciada. Resumindo o raciocínio do qual partimos: discutida a Modernidade, cumpre discutir também os conceitos que lhe são mais caros. Numa próxima oportunidade falaremos de outras ferramentas que são profundamente ligadas à própria constituição dessa etapa, mas desde já adiantamos crer que a crise, ou nova fase desta última, autoriza-nos a indagar sobre os rebatimentos e 
manutenção do poder explicativo além do alcance dos estudos geodemográficos se estes não levam tal momento em consideração.

População é um conceito gestado e nascido no âmbito da alta Modernidade, ou seja, quando esta já se achava consolidada em seus pilares básicos. Deste modo, em que pese o fato de se constituir num intervalo de tempo bastante amplo, cujas raízes podem facilmente reportar-se ao século $\mathrm{XV}$, interessa-nos aqui apenas o período em que seus pressupostos basilares já se achavam plenamente estabelecidos, quais sejam: um pressuposto político representado, a um só tempo, pelas Revoluções Francesa e Americana; um pressuposto econômico representado pela Revolução Industrial; e, por fim, um pressuposto demográfico representado pelo advento e expansão do processo de urbanização nos países onde a Revolução Industrial deu-se inicialmente. Estamos, portanto, tratando de um período bem específico, os tempos modernos que nutriram-se da atmosfera vicejante nos grandes centros urbanos europeus da época. O que denominamos aqui de Modernidade refere-se ao período que se inicia mais ou menos em meados do século XVIII, vindo até nossos dias qualquer que seja a denominação que se lhe atribua na atualidade, (modernidade reflexiva ${ }^{6}$ ou mesmo pós-modernidade, por exemplo).

Como marca básica de sua vigência, a Modernidade tem o aparecimento e estruturação da racionalidade, mais especificamente a racionalidade técnico-instrumental (HANSEN, 1999) que, por sua vez, possui suas raízes nos novos contornos que o capitalismo passa a assumir. O Estado Nacional, artífice privilegiado nesse novo cenário conta com a população (enquanto conceito e dado concreto), como um ente especialmente importante na função de planejar e de implementar suas prioridades. Como bem pontua o geógrafo Paulo Cesar da Costa Gomes:

\begin{abstract}
"Entre o Estado planificador dos anos trinta, criador de projetos, gerenciador, e as iniciativas dos serviços públicos, produção de dados e materiais para o reconhecimento do terreno, das administrações dos séculos XVIII e XIX, existe uma forte correspondência". (GOMES,1999, p. 58 e 59).
\end{abstract}

Podemos, então, alinhar alguns aspectos dessa ligação atendo-nos a seu estreito parentesco com requerimentos do Estado no seu afã de administrar o conteúdo de suas fronteiras, seu território. A atenção, por assim dizer, para com o temário demográfico não é privilégio do período destacado, mas dá-se em termos bastante diversos daqueles postos à partir de meados do século XVIII. Na Antiguidade, por exemplo, a preocupação básica do 
soberano era para com a degradação do número de súditos, o despovoamento de seu reino ou de alguma região em específico. Não há neste momento, conceitualmente falando, algo que se assemelhe à "população" em seu entendimento moderno. $\mathrm{O}$ "depopulátio" ou a “despopulação" era o designativo mais próximo, encarregado de resumir tal processo de declínio, que poderia se dar por conta de alguma tragédia natural, alguma peste ou mesmo a devastação imposta por guerras ${ }^{7}$. Despopulação denota aqui as preocupações com o número de pessoas apenas e tão somente no que dizia respeito às características e razões ligadas ao seu declínio numérico. As possibilidades de sua perda e, por conseguinte, a perda do poder decorrente desse processo é que realmente figuravam como pano de fundo da análise de qualquer questão demográfica. Como bem aponta Michel Foucault:

“(...) a questão da população não era colocada de maneira nenhuma em sua positividade e em sua generalidade. Era em relação a uma mortalidade dramática que se colocava a questão de saber o que é a população e como se poderá repovoar". (FOULCAULT, 1978, p.89).

É possível lembrar, aqui, as tábuas de mortalidade feitas na Inglaterra por John Graunt $^{8}$ como um perfeito exemplo dessa seletividade, por assim dizer, das preocupações ligadas à população. Graunt dá início aos estudos estatísticos sobre os habitantes da Inglaterra atendo-se especificamente à forma como cada cidadão de Londres sucumbia, e nesse sentido estava em perfeita consonância com seu tempo.

A contra-face, ou melhor o complemento a essa atmosfera dá-se a partir do enquadramento da população como elemento do poderio de um soberano, ou seja, resolvida a questão de sua escassez ou declínio estava posta a possibilidade de transformar seu número em fonte de poder. Isso decorria do fato óbvio de que nesse caso o soberano capacitava-se a dispor de tropas cada vez mais numerosas e, no entender de Foucault (1978), de que sendo populosas as cidades de seus domínios, seus mercados seriam dotados de uma, muito bem vinda, vivacidade econômica.

Realizar essa correção, no rumo do entendimento das questões demográficas, ou seja colocar em pauta sua positividade, seu crescimento, demandou em primeiro lugar a supressão deste viés mais simplificado - como mero grupamento de homens conduzidos pela vontade do soberano através de leis e decretos - em favor de um raciocínio que a converte em objeto técnico ${ }^{9}$ de um governo, como verdadeiro componente de seus 
mecanismos. Essa conversão pressupõe, por exemplo, uma despersonalização da relação entre as ações do Estado e a população:

"A imagem do Estado deixa gradualmente de ser representada por um personagem físico para tornar-se aquela de um território. A Revolução Francesa foi o marco desta mudança. Ela consagrou o desaparecimento da identificação direta entre o governante e o Estado, e a generalização de um mesmo conjunto de regras e de condutas para todo território. Foi também o mais célebre momento de uma verdadeira febre legisladora que pretendia dissociar completamente o privado do público o mais precisamente possível". (GOMES, 1999, p.58).

Outro movimento em favor da constituição desse objeto se dá a partir do estabelecimento da população como ente ou parte integrante de uma série de processos econômicos de formidável complexidade, não só porque não partiam diretamente do comportamento demográfico em si (não estavam confinados a ele, antes o antecedendo e o influenciando), mas também porque, ao se relacionar com a população, estes processos se quebravam numa infinidade de variáveis que não poderiam ser controladas senão mediante um sofisticado mecanismo de governo. Tomemos como exemplo o debate que se fez sentir sobre as leis que regulavam a importação de trigo na Inglaterra (SZMRECSÁNYI,1982). Nesta contenda não estava só em jogo uma reserva de mercado das oligarquias rurais inglesas, mas toda uma gama de repercussões sobre a concentração de população nos grandes centros urbanos e a migração que se poderia se intensificar no sentido campocidade.

Nesse sentido, a doutrina econômica utilitarista teve um papel bastante especial no estabelecimento de uma nova visão dos fenômenos demográficos por conta de suas características. Na medida em que se imiscuía dos processos econômicos, e no afã de administrá-los, o utilitarismo tomava a população como mais um componente que também deveria ser conduzido (ainda que mediante a ideologia liberal), aproveitando-se de suas características para chegar ao progresso econômico, ao invés de simplesmente estabelecer uma série de normas que deveriam ser obedecidas. Essa redução, do conjunto de pessoas que compunha o país dotado de uma infinidade de características e comportamentos individuais, para um componente do governo de um território, só poderia ser feita mediante o recorte de aspectos comuns para que pudessem ser alvo de algum tratamento estatístico. 
Neste momento o utilitarismo estava plenamente capacitado para realizar esse duplo movimento, pois (primeiramente) nivelava todos os homens a partir do que possuíam de mais básico e, portanto, estabeleciam essa universalidade em sua compreensão: sua busca pela satisfação de seus desejos ou, se quisermos ser mais fiéis à uma das figuras de maior proeminência dessa escola, sua busca pela felicidade (BENTHAN, 1823). Numa passagem, onde Michel Foucault (1978) lança mão de um exemplo repleto de espacialidade, essa redução revela suas qualidades ao governo dos homens. A aparição dessa nova "tecnologia política" captura e se aproveita daquilo que move a ação de cada indivíduo e contra a qual não se pode fazer nada, a busca da satisfação de seus desejos. Oportunamente nessa mesma passagem um fisiocrata como Quesnay é lembrado na medida em que afiança também este ponto de vista:

“(...) você não pode impedir as pessoas de virem morar onde consideraram que será mais proveitoso para elas e onde elas desejam morar, porque elas desejam esse proveito. Não procure muda-las, elas não vão mudar" (FOULCAULT,1978, p.95).

Diferentemente das tecnologias disciplinares, onde a norma recobre e orienta as ações de cada homem (estabelecendo um discernimento muito claro para se divisar aquilo que é considerado anormal), o aparecimento da população capacita ao governo dos homens partindo daquilo que possuem de mais natural e procura, na medida do possível, aproveitar-se deles e dessas suas características, buscando permear os indivíduos, ou melhor a população à essa técnica governamental:

(...) - esse desejo, por motivos sobre os quais será necessário tomar e que constituem um dos elementos teóricos importantes de todo o sistema, esse desejo e tal que, se o deixarmos agir e contanto que o deixemos agir, em certo limite e graças a certo numero de relacionamentos e conexões, acabará produzindo o interesse geral da população.(...) (A) Produção do interesse coletivo pelo jogo do desejo: é o que marca ao mesmo tempo a naturalidade da população e a artificialidade possível dos meios criados para gerila." (FOULCAULT,1978, p.95).

O outro lado desse movimento de redução, proporcionado pelo nascente utilitarismo, está na habilitação do entendimento do comportamento dos homens pelo viés estatístico ou, nas palavras de Hannah Arendt (1968), no cálculo da dor e do prazer que apresentava, entre suas vantagens mais sedutoras, a de introduzir o método matemático nas 
ciências morais. Não mais apenas a morte ou escassez de homens seria calculada, mas um número cada vez maior de variáveis seria introduzida nessa contabilidade de governo: sua vida, seus bens, sua migração, suas doenças, seu envelhecimento, etc..

Cremos, então, que nesse momento estamos aptos a entender como finalmente em meados do século XVIII, o filósofo David Hume propõe a criação de um novo vocábulo destinado ao estudo dos homens em sua relação com a economia das nações: o termo população. Hume, insatisfeito com termos como people, mankind ou populesness (correntemente utilizados pelos estudiosos da época) - e buscando se contrapor à suposição comum em seu tempo de que o mundo antigo fosse mais populoso que o moderno - acaba forjando um termo que resume os requerimentos e a assepsia necessária ao novo enquadramento dos fenômenos demográficos pelo liberalismo ${ }^{10}$ (LE BRAS, 2000).

Por fim, como bem resume Ruy Moreira(1993), estamos aqui tratando do nascimento de um novo homem, deslocado da natureza como resultante do postulado iluminista. Curiosamente também deslocado da sociedade, posto que entre outras missões do novo designativo estava, justamente, a sua distinção dos incômodos causados pelo termo povo nas pesquisas que então eram empreendidas. Daí não resultar espanto da transposição que vai ocorrendo à partir da aplicação de princípios universais ao comportamento da população (MALTHUS,1798) até sua introdução no campo pragmático da teoria econômica neoclássica ${ }^{11}$ que discorre com muita tranquilidade sobre as estatísticas apoiadas a esse novo homem ${ }^{12}$ (MOREIRA,1993).

\section{CONCLUINDO (PARA ESTABELECER NOVO PONTO DE PARTIDA)}

A adequação do conceito de população à Modernidade parece resultar de uma atmosfera muito propícia criada pelo casamento da racionalidade técnica com o liberalismo econômico, em especial sua vertente utilitarista, conforme tão bem demonstrou Michel Foucault nas passagens aqui destacadas. Dessa adequação deriva a desenvoltura com a qual esse conceito transitou, gozando não apenas de aceitação e prestígio, mas impondo-se como pedra angular na arquitetura teórica da própria Modernidade. Dada esta ligação tão enraizada parece-nos legítimo, então, perguntar se este mesmo conceito restará incólume diante do novo momento já apontado anteriormente. Aprimorando ainda mais nosso questionamento: haveria alguma chance de a população passar a contar com conceitos concorrentes e até mesmo mais apropriados, numa espécie de edição invertida do cenário já constatado para o século XVIII? 
Levado ao seu limite este raciocínio poderia nos fazer pressupor uma recorrência cada vez mais intensificada à conceitos e esquemas de pensamento até aqui menos funcionais aos estudos tipicamente advindos da racionalidade moderna. Veja-se, por exemplo, o contínuo esforço que tem sido empreendido nas ultimas décadas para sistematizar uma proposta que supere a separação entre o científico e o artístico no entendimento do homem, que emerge nesse cenário de crise da Modernidade. Nessa dissolução poderíamos perfeitamente encaixar, a título de exemplo, os estudos que transitam (ou pelo menos o intentam) no terreno entre a literatura ${ }^{13}$ e o conhecimento advindo de uma ciência concebida e sistematizada na Modernidade como é o caso da Geografia. Nesse debate, como é óbvio de se supor, o conceito de população ao contrário da atmosfera anterior - na qual circulava com desenvoltura e se revestia facilmente de relevância- tem flagrante dificuldade para se acomodar. Ainda que seja possível encarar essa busca como mera exploração de novas possibilidades na descrição do homem e de seu lugar no espaço, mas e se encarássemos essa procura como uma confissão da própria Modernidade de que suas geometrias estão revelando um ineludável esgotamento?

A resposta, em nosso entender, deve conter a consideração de um duplo aspecto desse momento. De um lado é preciso se levar em conta que os elementos básicos da Modernidade acham-se ainda em plena vigência. A racionalidade técnico-instrumental é um desses elementos, como bem nos demonstra Jurgen Habermas (1968). Essa adequação constitui-se numa decorrência natural de sistemas de ações que demandam qualidades contidas perfeitamente no conceito de população.

"a forma racional da ciência e da técnica, isto é a racionalidade materializada em sistemas de ação racional teleológica acaba por constituir uma forma de vida, uma "totalidade histórica" de um mundo vital.”(HABERMAS, 1968, p.55).

Outro aspecto, sem dúvida, é o Estado Nacional que em suas ações demanda um conhecimento sobre o território e seus conteúdos - dentre eles a população. Ocorre, porém que, do mesmo modo, uma ligação tão estreita com a Modernidade parece desembocar numa forma de como a população passará a ser estudada, caracterizada por novos instrumentos de consideração dos dados demográficos. Herve Le Bras (2000), por exemplo, faz uma oportuna lembrança do trabalho do historiador Reinhart Koselleck (1999) e de sua demonstração sobre: 
“(...) como os receios de uma situação apocalíptica do mundo, nos séculos XVI e XVII, recuam, (e) acabam por se converter na ideia do progresso sem limite que se estrutura a partir da Revolução Francesa" (LE BRAS,2000, p. 28 e 29).

Desse modo então (e ainda segundo esse ultimo autor citado), a população surge como ponto de referência entre os teóricos da decadência e os que afiançam a ideia de um progresso sem limites ${ }^{14}$. Assim, os estudos que tentam capturar o "desenvolvimento", conceito derivado da demarcação acima destacada, vão se sucedendo e aperfeiçoando seus instrumentos de mensuração cada vez mais adequados à aferição da expansão do consumo e do condicionamento das forças produtivas aos requerimentos desse modo de produção. Assim, a aferição dos diferentes níveis de desenvolvimento a partir da contagem do acesso à bens, renda e serviços pode ser citada como um exemplo da definição desse embate e a vinculação dos estudos de população à Modernidade ${ }^{15}$.

Ora, o que poderá ocorrer com os estudos de população, quando essa fé no progresso e no desenvolvimento passa a sofrer reveses cada vez maiores no campo da pesquisa acadêmica, a ponto de ser discutida até mesmo sua existência? Arriscando uma simplificação, aqui necessária, podemos responder que a evolução de diferentes sociedades passa a ser aferida de formas cada vez mais diversas e desvinculadas dessa mesma ideia de progresso e de desenvolvimento, tomados na acepção acima explicitada. Ainda que tal processo não seja tomado apenas em seu sentido negativo, uma vez que fustiga a busca por novas concepções e instrumentos de medida do estado de cada sociedade, é certo que solapa os raciocínios construídos à partir das concepções tradicionais de estudar a população.

Poderíamos, inclusive, lembrar da categoria "trabalho" como um tema especialmente caro à Modernidade e que se vincula aos estudos demográficos, quase se impondo como seu sinônimo (no caso da vertente marxista dos estudos de população). Nesse âmbito temos uma contestação à sua centralidade e, portanto, ao seu poder explicativo da realidade de cada país. Como bem assinala Ricardo Antunes (2007) na ênfase de sua produção mais recente: autores como Andre Gorz (1980), Jurgen Habermas $(1987)^{16}$ ou Anthony Giddens (1995) vem continuamente contestando essa centralidade do trabalho nos tempos da chamada Pós-modernidade. Ainda que aceitemos a argumentação de Antunes, no sentido de uma reafirmação do papel protagonista desse conceito, e da classe trabalhadora ainda em nossos dias, o fato é que mesmo assim temos de recompor nossas pesquisas à luz de uma abordagem ampliada dessa mesma classe ${ }^{17}$ o que, por sua 
vez, deve repercutir nos instrumentos de aferição dos níveis de emprego e da capacidade de inclusão de cada economia nacional ${ }^{18}$.

Fechamos esse breve artigo concluindo que qualquer uma das frentes que se abrem a pesquisa demográfica irá repercutir num novo modo de enquadrar a população e sua relação com o espaço. Resta-nos aprofundar cada uma dessas questões tomando-as como um roteiro que uma vez seguido, deve desembocar num renovação na forma como retratamos os fenômenos demográficos e espaciais.

\section{NOTAS}

1 - Em nosso caso, especificamente a Geografia.

2 - Nas palavras do autor: "considera-se "pós-moderna" a incredulidade em relação aos metarrelatos. É, sem dúvida, um efeito do progresso das ciências; mas este progresso, por sua vez, a supõe. Ao desuso do dispositivo metanarrativo de legitimação corresponde sobretudo a crise da filosófica metafísica e a instituição universitária que dela dependia" (LYOTARD,1979, p.xvii).

3 - Veja-se, por exemplo, o questionamento à categoria "trabalho" empreendida por Andre GORZ (1982).

4 - GIDDENS, BECK e SCOTT (1995).

5 - HARVEY (1989).

6 - BECK, Ulrich. (1995) A reinvenção da política: rumo a uma teoria da modernização reflexiva. In: BECK,U.; GIDDENS, A.; LASH, Scott 1997, p. 11-71.

7 - Sobre este vocábulo, despopulação, ver também Le Bras (2000). Segundo o autor sua antecedência ao termo população contém um indício importante onde o fenômeno precede sua avaliação: "No caso, os estragos da guerra ou das epidemias implicavam, quando atingiam um grau extremo, uma rarefação dos habitantes ou mesmo o seu desparecimento local"( op. cit., p.16).

8 - Citado por FOUCAULT (1978). Ver ainda STRATHERN (2003).

9 - Na colocação de FOUCAULT(1978), um "objeto técnico-político"(p.92). Aqui, contudo, assumiremos a expressão pura e simples de objeto técnico tendo em vista considerarmos sua similitude com a acepção assumida por Milton Santos(1996) e Simondon(1958). Sobre nossas reflexões quanto à possibilidade de encarar o conceito de população como objeto técnico, ver nossos argumentos em MILLÉO (2007) onde defendemos posição similar em relação aos indicadores sociais.

10 - É bastante conhecida a polêmica estabelecida entre David Hume e Robert Wallace sobre esta crença. No caso de Hume, este estabelece seu ponto de vista na obra Discursos Políticos, de 1752, mais especificamente no capítulo Of the Populousness of Ancient Nations. Robert Walace, por sinal, está entre aqueles que resiste num primeiro momento à adoção do novo vocábulo proposto por Hume. Seu contraponto à Hume intitula-se justamente: A dissertation on the numbers of mankind in ancient and modern times, editado em 1753 (SMERECSÁNYI,1982).

11 - Referimo-nos a autores como o inglês William Stanley Jevons (1835-1882) ou o francês Léon Walras (1834-1910).

12 - Nas palavras do autor, que merecem lembrança : "um homem transformado em estatística de produção e consumo, num mundo de natureza transformada em estoque de recursos naturais. Homem e natureza jogados numa mesma sorte" (Moreira,1993:39).

13 - Na verdade, bem podemos ressalvar que não se trata propriamente de exploração de uma nova fronteira de conhecimentos, mas antes mais uma crítica ao culto desmedido à racionalidade moderna. Sobre tal crítica ver os interessantes ensaios contidos em MARANDOLA JR, et al(2010).

14 - Sobre essa crença no progresso, como destino incontornável, é preciso lembrar que Robert Nisbet (1980) aponta que, já ao final dos anos 1950, tal conviçção começou a entrar numa rota de inquestionável declínio. 15 - Para mais detalhes sobre essa vinculação entre a Modernidade e seus instrumentos de aferição do progresso ver nossa exposição em MILLÉO (2005). 
16 - Citado em ANTUNES (2007).

17 - Tal como sugere o próprio Antunes em sua recente produção.

18 - NEGRI E HARDT (2004), por exemplo, defendem uma concepção ampliada de classe trabalhadora, a multidão.

\section{REFERÊNCIAS BIBLIOGRÁFICAS}

ANTUNES, Ricardo Adeus ao trabalho? São Paulo: Editora Cortez e Editora da UNICAMP, 2007.

ARENDT, Hanna (1958) A Condição Humana. 10 ed. Rio de Janeiro: Forense Universitária, 2001.

FOULCAULT, Michel (1978) Segurança, território e população. São Paulo: Editora Martins Fontes,2008.

Fontes,2008.

(1979) Nascimento da biopolítica. São Paulo: Editora Martins

GIDDENS, Anthony, BECK, Ulrich e LASH, Scott (1995) Modernização reflexiva. São Paulo: Editora UNESP, 1997.

GOMES, P. C. da Costa Geografia e modernidade. Rio de Janeiro: Editora BertrandBrasil,1996.

GORZ, Andre (1988) Metamorfoses do trabalho. 2ºdição, Rio de Janeiro: Editora Annablume, 2007.

Adeus ao proletariado: para além do socialismo. Rio de Janeiro:Editora Forense, 1982.

HABERMAS, Jurgen Técnica como ciência e como Ideologia. Lisboa,Portugal: Editora Edições 70, 1968.

HANSEN, Gilvan Luiz Modernidade, utopia e trabalho. Londrina: Edições CEFIL. 1999.

HARVEY, David (1989). A condição pós-moderna. São Paulo: Loyola, 1993.

HUME, David(1752). Of the populousness of ancient nations. In Essays, Moral, Political, and Literary. Indianapolis: Liberty Fundation.1987. P. 41-58. Disponível em : www.econlib.org/library/LFBooks/Hume/hmMPL34.html\#Part II, Essay XI, OF THE POPULOUSNESS OF ANCIENT NATIONS. Acesso em 28/08/2014.

KOSELLECK, Reinhart (1979). Futuro do passado:contribuição à semântica dos tempos históricos. Rio de Janeiro: Editora Contraponto e Editora PUC-Rio, 2006.

LE BRAS, Herve A invenção das populações. Lisboa: Editora Instituto Piaget, 2000.

LYOTARD, Jean-François (1979) O pós-moderno. $3^{\circ}$ edição. Rio de Janeiro :Editora José Olympio ,1990.

MILLÉO, José Carlos. A utilização dos indicadores sociais pela Geografia : uma análise crítica. Tese de doutorado. Niterói : Universidade Federal Fluminense, 2005. Disponível em http://www.bdtd.ndc.uff.br/tde_busca/index.php

MARANDOLA JR, Eduardo; GRATÃO, Lúcia Helena Batista (orgs.). Geografia e Literatura: ensaios sobre geograficidade, poética e imaginação. Londrina:EDUEL, 2010. 
MILLÉO, José Carlos Geografia e indicadores sociais: buscando o estabelecimento de bases para uma aproximação mais fecunda. Revista Geographya, Niterói,ano IX, $\mathrm{n}^{\circ}$ 18,pp.55-64, 2007.

MOREIRA, Ruy $O$ círculo e a espiral, a crise paradigmática do mundo moderno. Rio de Janeiro, Editora Obra Aberta, 1993.

NEGRI, Antonio e HARDT, Michael Multidão, guerra e democracia na era do Império. Rio de Janeiro: Record, 2004.

NISBET, Robert(1980). História da idéia de progresso. Brasília. Editora Instituto Nacional do Livro e UNB.1985.

SANTOS, Milton (1996) A Natureza do Espaço. São Paulo: EDUSP, 2002.

SIMONDON, Gilbert (1958). El modo de existencia de los objetos técnicos. Argentina, Prometeo Libros Editorial, 2007.

SZMRECSÁNYI, Thamás(org). Malthus. São Paulo: Editora Ática, 1982.

SMOLKA, Piotr A sociologia da mudança social. Rio de Janeiro: Editora Civilização Brasileira, 1993.

STRATHERN, Paul(2002). Uma breve história da economia. Rio de Janeiro: Jorge Zahar, 2003.

VALADE, Bernard (1992). Mudança social. In: BOUDON, Raymond et al. Tratado de sociologia. Rio de Janeiro: Editora Jorge Zahar, 1995. 